\title{
NOGO-B promotes EMT in lung fibrosis via MMP14 mediates free TGF-beta1 formation
}

\author{
Ye Xiong ${ }^{1, *}$, Jing Zhang ${ }^{2, *}$, Lingzhi Shi ${ }^{3,4, *}$, Yunye Ning ${ }^{1}$, Ying Zhu ${ }^{1}$, Si Chen ${ }^{1}$, Meng \\ Yang $^{1}$, Jingyu Chen ${ }^{4}$, Guo-Wu Zhou ${ }^{1,6}$ and Qiang Li ${ }^{1,5}$ \\ ${ }^{1}$ Department of Respiratory Medicine, Changhai Hospital, Second Military Medical University, Shanghai, China \\ ${ }^{2}$ Department of Pathology, Changhai Hospital, Second Military Medical University, Shanghai, China \\ ${ }^{3}$ Department of Respiratory Medicine, Wuxi People Hospital, Nanjing Medical University, Nanjing, China \\ ${ }^{4}$ Jiangsu Province Key Laboratory of Organ Transplantation, Wuxi People Hospital, Nanjing Medical University, Nanjing, China \\ ${ }^{5}$ Department of Respiratory Medicine, Shanghai First Hospital, Shanghai Jiaotong University, Shanghai, China \\ ${ }^{6}$ National Clinical Research Center for Respiratory Diseases, Center for Respiratory Diseases, Department of Pulmonary and \\ Critical Care Medicine, China-Japan Friendship Hospital, Beijing, China \\ *Authors contributed equally to this work \\ Correspondence to: Guo-Wu Zhou, email: gwzhou51@163.com \\ Qiang Li, email: liqres@hotmail.com \\ Keywords: Nogo-b, MMP14, idiopathic pulmonary fibrosis (IPF), epithelial mesenchymal transition (EMT), TGF-beta 1 \\ Abbreviations: Nogo-b: reticulon 4-b; MMP14: matrix metallopeptidase 14; IPF: Idiopathic pulmonary fibrosis; EMT: Epithelial \\ mesenchymal transition; TGFbeta 1: transforming growth factorbeta 1 \\ Received: April 04, $2017 \quad$ Accepted: July 19, $2017 \quad$ Published: August 16, 2017 \\ Copyright: Xiong et al. This is an open-access article distributed under the terms of the Creative Commons Attribution License 3.0 \\ (CC BY 3.0), which permits unrestricted use, distribution, and reproduction in any medium, provided the original author and source \\ are credited.
}

\section{ABSTRACT}

Idiopathic pulmonary fibrosis (IPF) is a lung disease with an extremely poor prognosis. Epithelial mesenchymal transition (EMT) appearing on the airway epithelial cell plays an essential role in the formation and development of Idiopathic pulmonary fibrosis. In this paper, Bleomycin (BLM)-induced mice model combined with bioinformatics analysis were employed to elucidate the potential mechanism of EMT in pulmonary fibrosis. The obtained results showed that endoplasmic reticulum protein Nogo-b may promote MMP14-mediated proprotein maturation of TGF- $\beta 1$, accelerating the release of free TGF- $\beta 1$ in type II airway epithelial cells A549, subsquently, induce the epithelial-mesenchymal transition (EMT) of the cell. In all, the overexpression of Nogo-b play a role in the course of pulmonary fibrosis by influencing the EMT ability of cells.

\section{INTRODUCTION}

Losing control of wound healing process in response to tissue injury may lead to tissue overgrowth, fibrosis, and organ failure, one of the adverse consequences of fibrotic diseases is that it can affect many organs, especially for lungs [1-2]. Normal pulmonary fibrosis is pathologically featured with aberrant activation of epithelial mesenchymal transition (EMT) of airway epithelial cell accompanied by inflammation, fibroblast proliferation, and excessive collagen deposition [3-9]. EMT, as a leading factor for the pathogenesis of normal lung parenchyma replacement, is characterized by loss of epithelial characteristics (E-cadherin) and has acquired mesenchymal phenotype including $\mathrm{N}$-cadherin, vimentin and smooth muscle actin ( $\alpha$-SMA) [10]. And also it was reported that the EMT process in lung fibrosis largely induced by the TGF- $\beta 1$ via increasing the expression of the SNAI transcription factors [9], which is consistent with the recent reports on that EMT plays the key roles for pulmonary fibrosis [10-11]. Thus, it is of great significance to deeply understand the mechanisms of EMT of airway epithelial cell in pulmonary fibrosis. In addition, TGF- $\beta 1$ induced disturbances of the homeostatic microenvironment resulted in Idiopathic pulmonary fibrosis (IPF) [12]. Idiopathic pulmonary fibrosis (IPF), as a kind of fibrotic diseases, has an extremely poor prognosis for patients, which is worse than that of 
numerous cancer patients in survival [13]. So far, in clinic, anti-inflammation drugs have been adopted as a long-term effective pharmaceutical treatment in a number of cases. Whereas, IPF suffers benefited few from these drugs. so it is urgent to develop new approaches to overcome this problem.

Nogo-b, a member of the endoplasmic reticulum protein family, is located on the endoplasmic reticulum and cellular membrane and abundant in peripheral tissues including lung [14]. It plays a vital role in repairing and regenerating the vascular and in the process of hepatic fibrosis [15-16]. Meanwhile, researches revealed that Nogo-b could promote cell migration in numerous tumors by intensifying EMT. In addition, our previous works showed that Nogo-b was essential for the migration and contraction of smooth muscle cells for airway and the acute lung injury induced by LPS [17]. However, there are only few researches on the performance of Nogo-b for pulmonary fibrosis and in the process of EMT concerning pulmonary fibrosis.

Matrix metalloproteinase 14 (MMP14) is a kind of membrane-type matrix metalloproteinases. It has a C-terminal transmembrane domain and a cytoplasmic tail [18]. Although MMP14 has been studied in a number of tumor cases and has long been considered it was correlated with EMT and featured with a capacity of enhancing cell invasion and migration [18-19], little is known about its significances in IPF [20-22].

In this study, we identified the effect of Nogo-b in EMT of and discussed its relationship with MMP14, which further clarify the effect of Nogo-b/MMP14 on EMT, as well as the role of EMT in the pathogenesis of IPF.
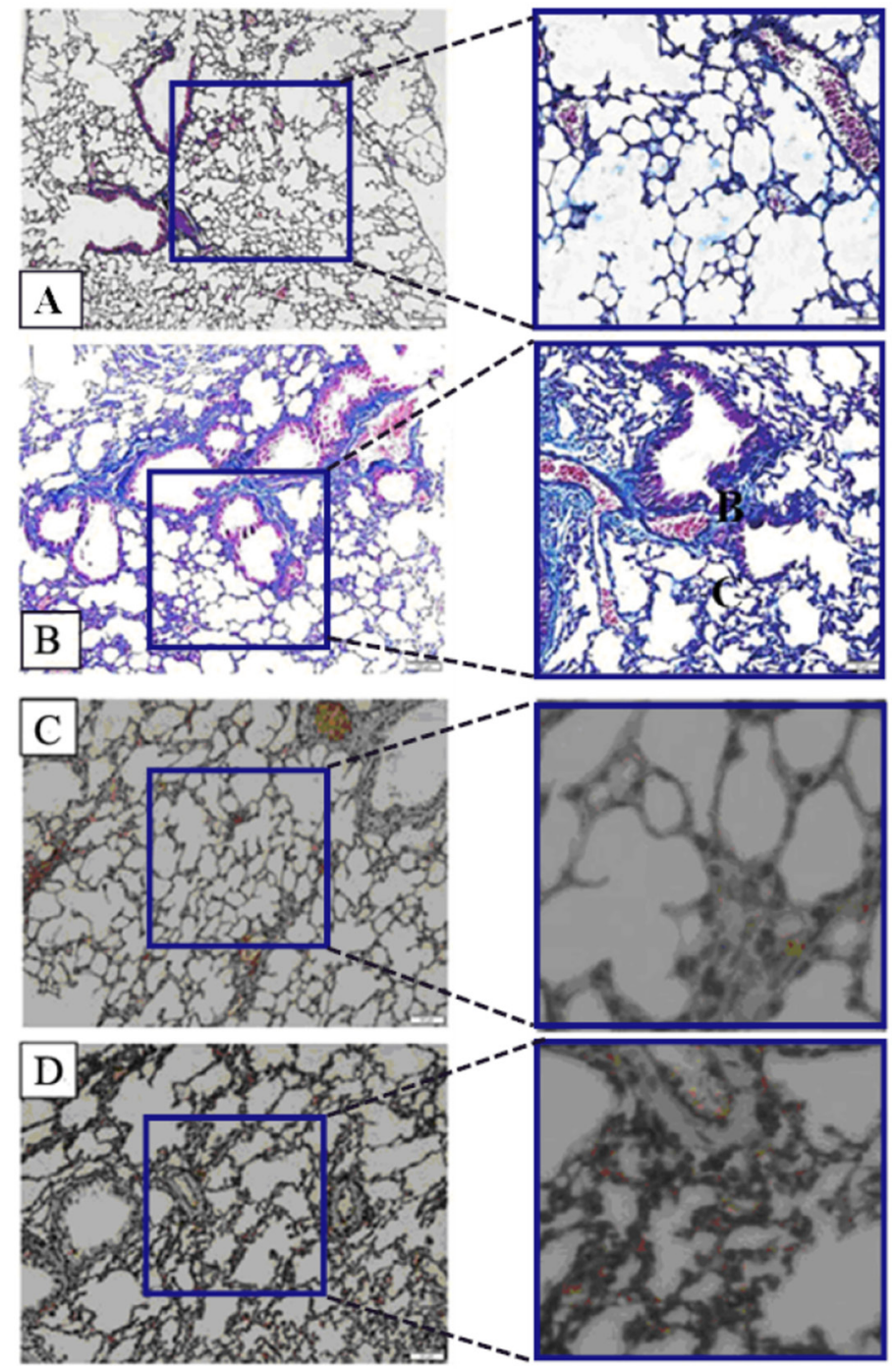

Figure 1: Nogo-b is up-regulated in a mouse model of bleomycin induced pulmonary fibrosis. Representative images of Masson staining control lung tissue (A) and lung tissue in a model of BLM-induced pulmonary fibrosis (B). Representative images of Nogo-b immunohistochemical staining control lung tissue (C) and lung tissue in a model of BLM-induced pulmonary fibrosis (D). 


\section{RESULTS}

\section{Ectopic expression of Nogo-b was observed in pulmonary fibrosis induced by bleomycin}

First, Masson staining was used to identify the BLM-induced pulmonary fibrosis model in mice. As can be seen in Figure 1, Lung tissues in the control group are featured with continuous structure, intact wall of bronchial mucous membrane and normal lung alveoli. Smooth muscle cells surrounding the bronchial wall are red. Slight blue stain is seen around bronchus and vessels of all levels (Figure 1A). However, the BLM-based group revealed the increased alveolar wall. The structure of alveolar wall was damaged. Most of the area within the field of view presented bundles- or patches-shaped blue blocks (Figure 1B). It means huge deposition of collagen and fibronectin (one of the typical performances of pulmonary fibrosis, frequently accompanied by EMT). In order to determine whether protein expressions were associated with pulmonary fibrosis, Immunohistochemistry (IHC) was applied to examine the difference in the expression level of Nogo-b in lung samples of mice between the group treated with BLM and the untreated control, It was found that the lung mesenchyme in the mice treated with BLM showed a stronger brown staining for Nogo-b (Figure 1D) than that for the normal group (Figure 1C), indicating that high expression of Nogo-b is one of the features for the fibroblastic foci induced by BLM.

\section{Nogo-b can promote the EMT in type II alveolar epithelial cells}

In this section, we examined the effect of Nogo-b on EMT. Using TGF- $\beta 1$ as a positive stimulator, we compared Nogo-b over-expression A549 cells and normal A549 cells in terms of the three major EMT markers: Vimentin, $\alpha$-SMA and E-cadherin. For the sample treated with TGF- $\beta 1$, its mRNA level of Vimentin and $\alpha-S M A$ was significantly increased $(\mathrm{p}<0.05)$ in 48 hours, and the mRNA of E-cadherin decreased to almost the half of the control (Figure 2A). and the level of the protein expression of the Vimentin, $\alpha$-SMA and E-cadherin showed the same trend with the mRNA. That is, the TGF- $\beta 1$ stimulated A549 cell had nearly twice the level in Vimentin and $\alpha$-SMA, almost half for the E-cadherin, compared to the control (Figure 2B). for the sh-Nogo-B treated sample, the Vimentin, $\alpha$-SMA and E-cadherin were same with control in the level of both mRNA and protein. while for the the A549 cells transfected with pcDNA3.1-Nogo-b, the corresponding mRNA and protein for Vimentin, $\alpha$-SMA and E-cadherin were similar to that of TGF- $\beta 1$ treated samples. In conclusion, these data indicate that Nogo-b can promote the EMT in type II alveolar epithelial cells.

\section{Analysis of differentially expressed genes (DEGs)}

The disease progress of pulmonary fibrosis is very complicated. A group of microarray data on the lung genes of mice induced by BLM were employed for the purpose of further studying the key genes affecting the occurrence and development of pulmonary fibrosis. The original data of GSE25640 was downloaded from GEO. Then the expression profile data was analyzed by Affy package in $\mathrm{R}$ language. Microarray data included a total of 5004 genes. Cassette figures after data standardization were shown in Figure 3A. All the black lines appearing in a straight line revealed a good standardization. By comparing the microarray data for the wild-type C57BL/6 mice treated with normal saline with that for the wild-type C57BL/6 mice treated with BLM, a total of 278 DEGs (accounting for $5.3 \%$ of the total genes) were discovered, including 172 up-regulated genes and 106 down-regulated ones (Figure 3B). Hierarchy cluster analysis indicated that the genes for three groups treated with Bleomycin distributed in a cluster and genes for another three groups treated with
A

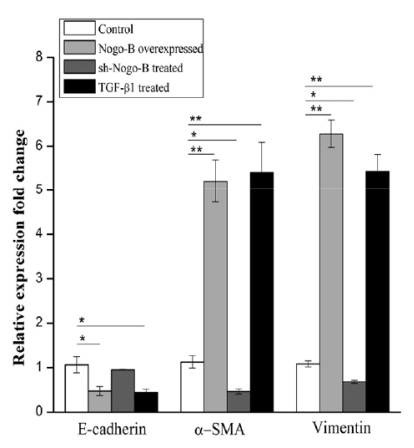

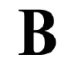

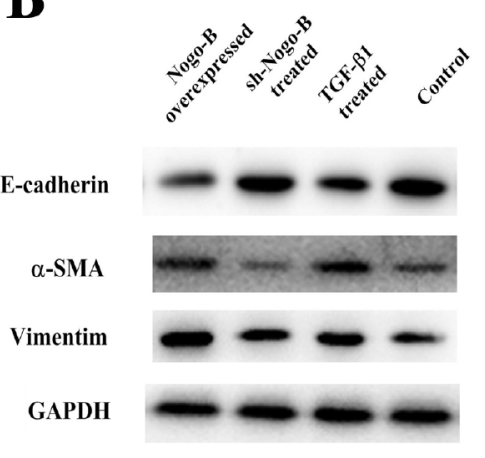

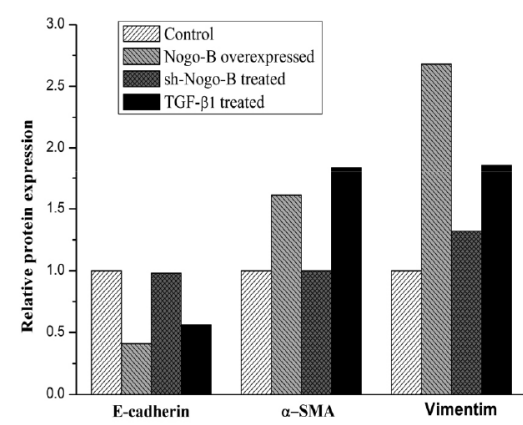

Figure 2: Overexpression of Nogo-B promotes EMT in A549 cell. RT-PCR analysis (A) and Immunoblot analysis (B) of Marker proteins (E-cardherin, $\alpha$-SMA and Vimentin) which were relative to the EMT in the A549 cells treated with Nogo-B overexpressed, shNogo-B and additional TGF- $\beta 1$ respectively. (The mRNA expression of Nogo-B in A549 cell lines was relative to the GAPDH mRNA from the same sample). All data are expressed as the mean \pm SD of at least three. 
normal saline distributed in another cluster (Figure 3C). The results showed that the sequencing data was credible and may be directly applied to further analysis.

\section{Function and pathway enrichment analysis}

278 DEGs in gene list were uploaded to DAVID website. Based on the GO analysis, the enrichment pathways with the value of $\mathrm{P}$ less than or equal to 0.05 were obtained (Figure 4A). The GO pathways with highest enrichment were listed, from which we found that most of them were correlated with the extracellular region and extracellular region part. Top GO pathways with highest degree of enrichment were shown in Figure 4A.

We also carried out KEGG analyses on DAVID website (Figure 4B). Results revealed that interaction between cytokine and cytokine receptor was the KEGG pathway deserving our greatest attention. Among top 10 KEGG signal pathways and top $10 \mathrm{GO}$ signal pathways with highest degree of enrichment, there were 17 flapped DEGs likely to be correlated to pulmonary fibrosis induced by BLM. The 17 flapped DEGs are: SOCS3, Cc19, MMP14, Igf1, Aox3, C1qa, C1qb, C3ar1, Cc112, Cc12, Cc18, Cc19, Cxc110, Fcgr1, Gsta2, Kngl and Pdgfc. Then, we tested changes in mRNA level using the method of RT-PCR based on the BLM-induced pulmonary fibrosis model that we built by ourselves. The results showed that differential expressions were existing in MMP14, Ccl9, Socs3, Igf1, C1qa, C1qb, Ccl12, Ccl2, Ccl8, Cxcl10 and Gsta2. Verification results by RT-PCR are listed in Table 1. Among these candidate genes, MMP14 was selected as our target gene for further study, for it is considered to be the gene most likely to be correlated to pulmonary fibrosis and it has validated as the greatest differential expression genes in the list.

\section{Overexpression of MMP14 in type II alveolar epithelial cells generates a severe EMT phenotype}

To confirm whether MMP14 would also affect the pulmonary fibrosis through EMT in human, we performed

A

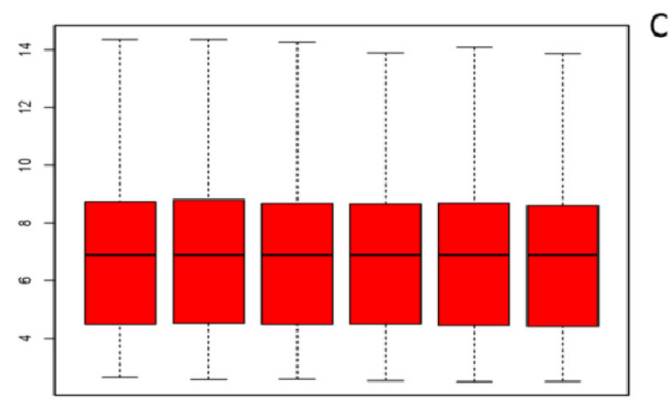

B

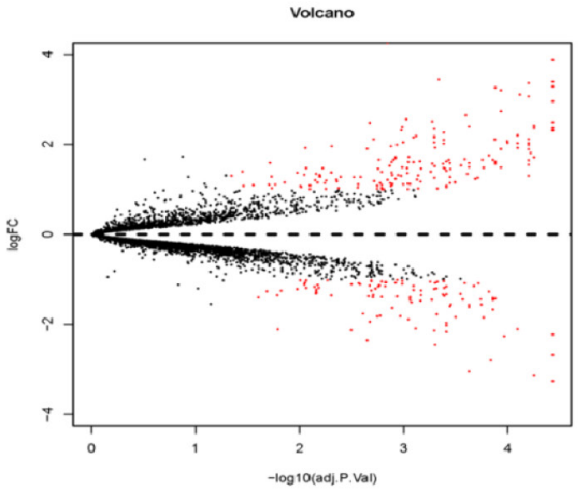

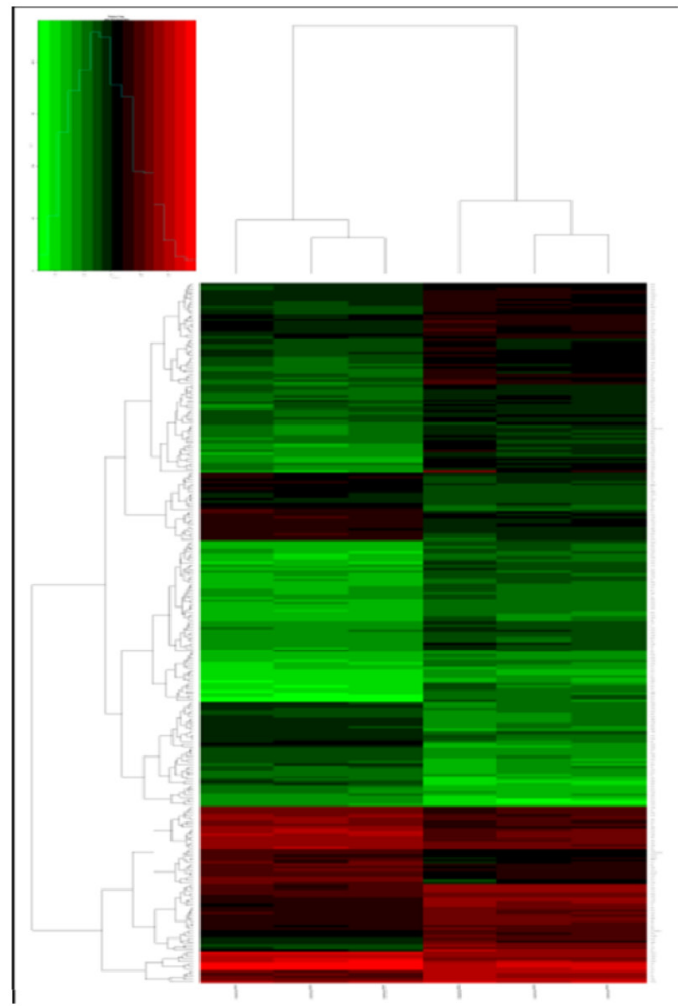

C

Figure 3: Analysis of DEGs by bioinformatics tools. (A) Cassette figures of data distribution after standardization. The horizontal axis stands for sample names while the vertical axis represents the expression That all the black lines in the figure are almost on the same straight line reveals a good standardization degree. (B) The volcano plot of differentially expressed genes. The abscissa is logFC and the ordinates is $-\log 10$ (P Value). The red dots stand for the differentially expressed genes while the black dots represent genes not differentially expressed. (C) Hierarchical cluster dendrogram of DEGs. The horizontal axis represents sample names. GSM629991 GSM629992 and GSM629993 are saline treated wild type mice samples. GSM629994, GSM629995 and GSM629996 are Bleomycin treated wild type mice samples. The left vertical axis shows clusters of DEGs, and the above horizontal axis shows clusters of samples. Red represents upregulated genes and green represents down-regulated genes. 
Table 1: Comparison of mRNAs by RT-PCR and RNA microarray

\begin{tabular}{|c|c|c|c|c|}
\hline GENE & RT-PCR & Microarray & P-Value for RT-PCR & Gene Name \\
\hline Socs 3 & 2.47 & 2.07 & $<0.050$ & $\begin{array}{l}\text { Suppressor of cytokine } \\
\text { signaling } 3\end{array}$ \\
\hline $\mathrm{Cc19}$ & 2.85 & 2.49 & $<0.050$ & $\begin{array}{l}\text { Chemokine (C-C motif) } \\
\text { ligand } 9\end{array}$ \\
\hline Mmp14 & 3.4 & 2.31 & $<0.050$ & Matrix metalloproteinase-14 \\
\hline Igf1 & 2.33 & 2.32 & $<0.050$ & Insulin-like growth factor 1 \\
\hline $\mathrm{C} 1 \mathrm{qa}$ & 2.51 & 2.31 & $<0.050$ & complement $\mathrm{C} 1 \mathrm{q}$ A chain \\
\hline $\mathrm{Clqb}$ & 2.33 & 2.37 & $<0.050$ & complement $\mathrm{C} 1 \mathrm{q}$ B chain \\
\hline $\mathrm{Ccl} 12$ & 2.1 & 2.64 & $<0.001$ & $\begin{array}{l}\text { chemokine (C-C motif) } \\
\text { ligand } 12\end{array}$ \\
\hline $\mathrm{Ccl} 2$ & 1.99 & 2.11 & $<0.050$ & $\begin{array}{l}\text { C-C motif chemokine } \\
\text { ligand } 2\end{array}$ \\
\hline $\mathrm{Ccl} 8$ & 2.88 & 3.36 & $<0.050$ & $\begin{array}{l}\mathrm{C}-\mathrm{C} \text { motif chemokine } \\
\text { ligand } 8\end{array}$ \\
\hline Cxcl10 & 2.36 & 2.02 & $<0.001$ & $\begin{array}{l}\text { C-X-C motif chemokine } \\
\text { ligand } 10\end{array}$ \\
\hline Gsta2 & -2.53 & -2.17 & $<0.001$ & $\begin{array}{l}\text { glutathione S-transferase } \\
\text { alpha } 2\end{array}$ \\
\hline
\end{tabular}

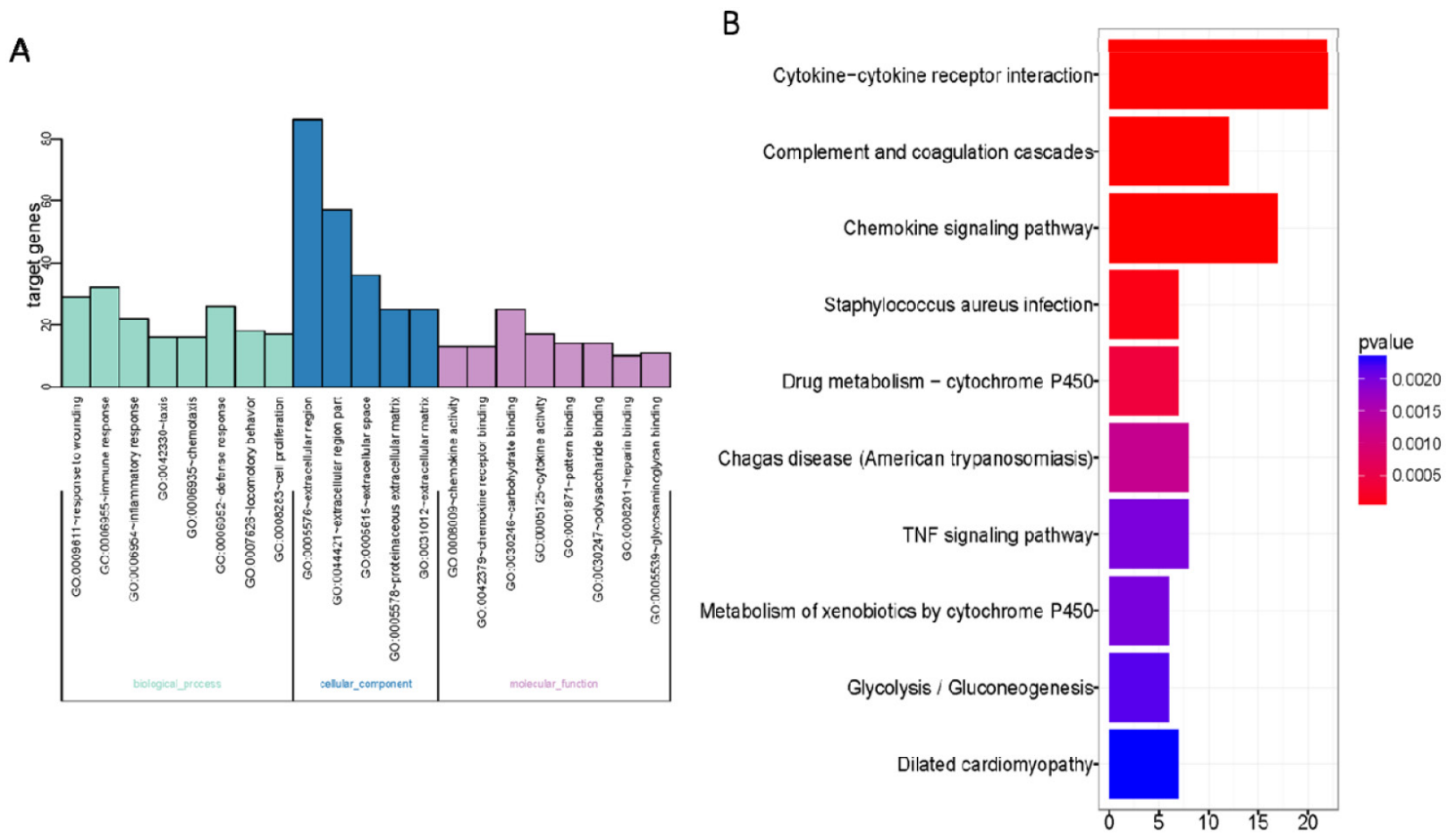

Figure 4: Gene Ontology enrichment analysis. (A) Gene Ontology enrichment of DEGs of Bleomycin treated wild type mice lung samples; (B) KEGG enrichment of DEGs of Bleomycin treated wild type mice lung samples. The horizontal axis represents the number of enriched genes. The vertical axis represents the Gene Ontology or KEGG terms. 
MMP14 over-expression and knockdown experiments in A549 cell. Over-expression and low-expression of MMP14 were verified by qRT-PCR and Western blot, as shown in Figure 5A and B. A significant up-regulation of MMP14 was observed when pcDNA3.1-MMP14 plasmid was transfected into A549 cell. And the down-regulation was observed when pLKO.1-shMMP14 plasmid was transfected into A549 cell.

Vimentin, $\alpha$-SMA and E-cadherin are widely accepted as EMT markers. In subsequent experiments, it was found that TGF- $\beta 1$, as an agonist of EMT, could induce a significant increase in level of agonist for vimentin and $\alpha$-SMA $(\mathrm{p}<0.01)$ (Figure 5C and 5D). Likewise, by comparing the A549 cell transfected by MMP14 for 48 hours with the negative control, it was found that its expressions of mRNA for Vimentin were also increased significantly $(\mathrm{p}<0.01)$ (Figure 5C). Meanwhile, protein of Vimentin would witness an increased as the rising mRNA level (Figure 5D). In our researches, the over-expression of MMP14 would induce the significant increase of expressions of mRNA and protein for $\alpha$-SMA (Figure 5C and 5D) $(\mathrm{p}<0.01)$ as well. E-cadherin mRNA was remarkably decreased 48 hours after MMP14 was transfected, accompanied by the declining of E-cadherin protein level $(p<0.01)$ (Figure 5C and 5D). 48 hours after the treatment of A549 cell by TGF- $\beta 1$, expressions of E-cadherin mRNA and protein were reduced. These results showed that MMP14 can stimulate A549 cell to manifest EMT features like TGF- $\beta 1$.

\section{Nogo- $b$ is identified as upstream controlling gene of MMP14}

In order to demonstrate the molecular mechanisms by which MMP14 influenced EMT in type II alveolar epithelial cells, a panel of molecules was predicted to be potential targets of the MMP14. Our team had proved the key function of Nogo-b in migration and contraction of airway smooth muscle cells and lipopolysaccharideinduced acute lung injury [15-16]. Researchers also reported that Nogo-b is able to promote EMT in HeLa cervical cancer cells via Fibulin-5 [23]. Is there any correlation between MMP14 and Nogo-b? In this study, Expression difference of the MMP14 between Nogo-b overexpression A549 cell line and normal A549 cells was further examined. Firstly, we examined the expression

\section{$\mathbf{A}$}

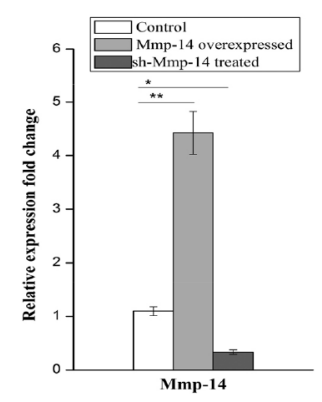

C

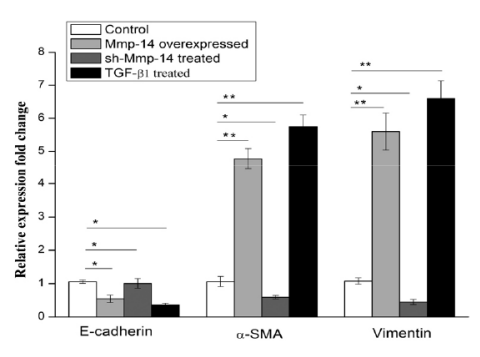

B
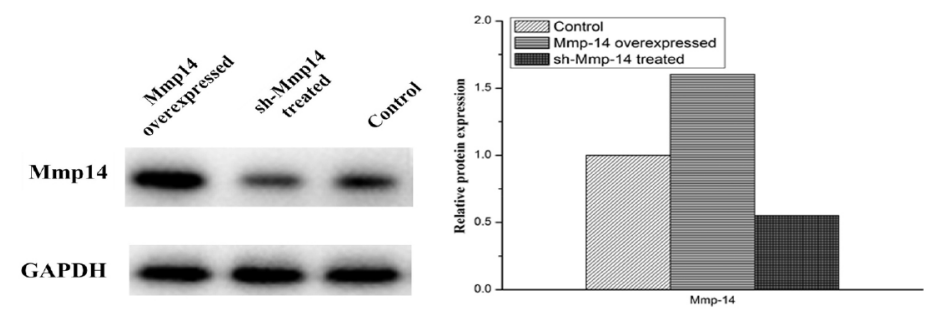

D

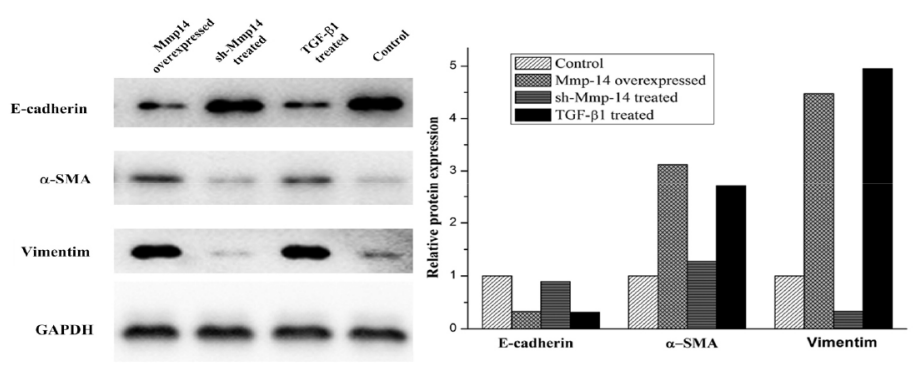

Figure 5: The protein and mRNA expression of Mmp14 in A549 treated with different ways. (A) the mRNA expression of Mmp14 in A549 cell lines was relative to the GAPDH mRNA from the same sample. The experiments were performed three times, and the mean value \pm SD are presented. (B) Western blotting of Mmp14 in Blank, Mmp14 overexpressed and sh-Mmp14 treated A549. And quantitative analysis of Mmp14 expression in A549 cells under the indicated treatment Overexpression of Mmp14 promotes EMT in A549 cell. mRNA analysis (C) and Immunoblot analysis (D) of Marker proteins (E-cardherin, $\alpha$-SMA and Vimentin) which were relative to the EMT in the A549 cells treated with Mmp14 overexpressed, sh-Mmp14 and additional TGF- $\beta 1$ respectively. (The mRNA expression of Mmp14 in A549 cell lines was relative to the GAPDH mRNA from the same sample). All data are expressed as the means \pm SD of at least three independent experiments. 
quantity of MMP14 in A549 cells containing overexpression of Nogo-b, results of which showed that MMP14 was higher in the A549 cells containing highexpression of Nogo-b than that in cell line containing low-expression of Nogo-b (Figure 6A and 6B). Such result promoted us to further study whether the expression of Nogo-b is affected by the abnormal expression of MMP14. It was found that A549 cells tranfected by lipo2000/pcDNA3.1-MMP-14 plasmids seldom changed in expressions of mRNA and protein of Nogo-b (Figure 6A and 6B). Moreover, knockout of Nogo-b using sh-RNA significantly reduced the expression of MMP14. However, remarkable expression differences of Nogo-b did not appear in A549 cells of MMP14 knockout (Figure 6C and 6D). Therefore, we can draw a conclusion that expression of MMP14 is regulated and controlled by Nogo-b.

\section{Up-regulation of $M M P 14$ rescues Nogo-b mediated EMT}

It was found that overexpression of MMP14, which is an upstream controlling gene of Nogo-b, could enhance EMT, based on which we hypothesized that Nogo-b could change the EMT of A549 by affect functions of MMP14. Silent A549 cells and normal A549 cells in Nogo-b were used as the experimental materials. As expected, shRNA which knocked down the Nogo-b remarkably reduced the EMT capabilities of A549 cells (Figure 7A and 7B). To further study EMT mechanism mediated by Nogo-b and MMP14 in type II alveolar epithelial cell model, we overexpressed MMP14 in silent A549 cells of Nogo-b. Results of which revealed that EMT capacities of cells would be intensified in cases where MMP14 was over expressed in A549 cells which knocked down by Nogo-b (Figure $7 \mathrm{~A}$ and $7 \mathrm{~B}$ ). These results further verified that Nogo-b could affect the EMT capacity of A549 cells by regulating MMP14.

\section{MMP14 can promote TGF- $\beta 1$ release from pro- proteins}

TGF- $\beta 1$ is widely known as the main cytokine involved in the pathogenesis of IPF, which can induce EMT on the model of A549 type II airway epithelial cells. Anti-TGF- $\beta$ therapy is commonly used to cure fibrosis diseases. TGF- $\beta$ family are translated as proproteins which can be activated and hydrolyzed by a number of proteases including MMP14. In this study, we hypothesized that the regulation of MMP14 by NOGO-B was performed by catalyzing the hydrolysis of TGF- $\beta 1$ pro-proteins and releasing TGF- $\beta 1$. To prove this point, we tested the expression quantity of TGF- $\beta$ mRNA in the silent model
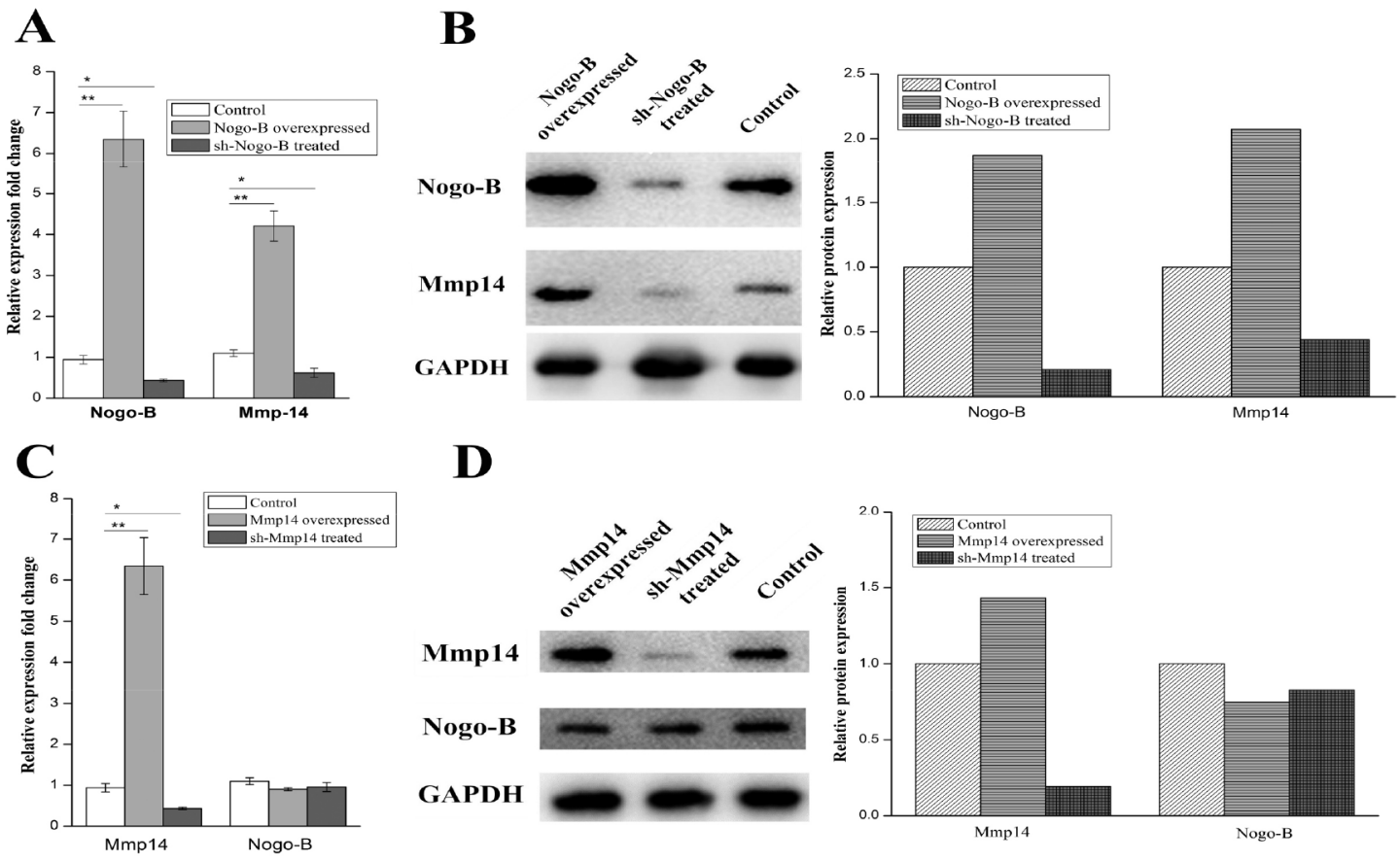

D

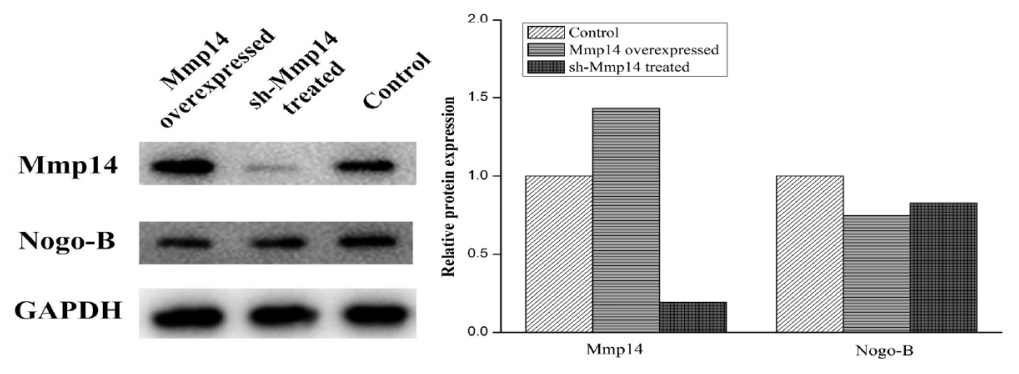

Figure 6: The protein and mRNA expression of the Mmp14 were in line with the up and down regulated Nogo-B in A549 cells. (A) qRT-PCR analysis of Mmp14 and Nogo-B levels in the A549 cells with indicated treatments. All data are expressed as the means \pm SD of at least three independent experiments. The protein and mRNA expression of the Mmp14 were influenced by the up and down regulated Nogo-b in A549 cells. (B) Western blot analysis of Mmp14 in A549 cells treated with overexpresion and silence of Nogo-B, GAPDH was used as a loading control. (C) qRT-PCR analysis of Mmp14 and Nogo-B levels in the A549 cells with indicated treatments. All data are expressed as the means \pm SD of at least three independent experiments. (D) Western blot analysis of Nogo-B in A549 cells treated with overexpresion and silence of Mmp14, GAPDH was used as a loading control. 
of MMP14, results of which showed that there were no obvious differences between the silent model and nonsilent model in expression of TGF- $\beta$ mRNA (Figure 8A). Meanwhile, we found that less free TGF- $\beta 1$ were observed in knockdown model of MMP14 while expression of TGF- $\beta$ proproteins in cell lysate was not significantly changed (Figure 8B). These results suggested that MMP14 cleaved TGF- $\beta$ proproteins in cell culture supernatants (Figure 9), which may be a molecular mechanism that Nogo-b/MMP14 pathway utilized to promote EMT of alveolar epithelial cells dependent by TGF- $\beta 1$.

\section{DISCUSSION}

Our study demonstrated that MMP14 played a critical role in EMT of pulmonary fibrosis, and the expression level of MMP14 determined the progress of EMT. Meanwhile, we discovered that Nogo-b could regulate the expression of MMP14. The absence of Nogo-b inhibited the expression of MMP14 while the absence of MMP14 would not affect the expression of Nogo-b. Moreover, it was identified that, Nogo-b could promote the EMT of A549 cell, and loss of MMP14 decreased the release of active TGF- $\beta 1$ but without any influences on the expression of TGFß proteinogen. In all, the obtained results demonstrated that MMP14 as a new downstream target of Nogo-b could mediate the promote pulmonary fibrosis, in addition, Nogo-b/MMP14 could regulate pulmonary fibrosis by affecting the process of cleaving TGFß proteinogens.

At present, although we have known that Nogo-b plays an important role in vascular injury repair, tissue repair and inflammation process [24-25], little is known about its functions in the lung. Previous works have shown that Nogo-b is irreplaceable for hepatic fibrosis
[15], so it attract interestings from us to speculate that the functions of Nogo-b maybe related to the pulmonary fibrosis. Meanwhile, we have known the fact that Nogo-b is critical for the migration and contraction of airway smooth muscle cells as well as LPS-induced acute lung injuries $[17,26]$, LPS-induced acute lung injuries are frequently accompanied by pulmonary fibrosis, and pulmonary fibrosis is also associated with the reconstruction of airway smooth muscles. In this study, whether Nogo-b had related functions for the process of pulmonary fibrosis were verified.

BLM is an antineoplastic drug which can induce pulmonary fibrosis [27]. Exposure of BLM can lead to fatal pulmonary toxicity, which is the most commonly used to set up IPF model of mice to study disease pathogenesis with the characteristics of the patchy parenchymal inflammation, the reactive epithelial hyperplasia and the epithelial-mesenchymal transition [16, 28-31]. In this study, it was firstly observed that high expression of Nogo-b in lung tissues of BLM-induced pulmonary fibrosis models of mice, indicated that Nogo-b is associated with the occurrence of pulmonary fibrosis diseases. Meanwhile, the injured airway epithelial cell became the fibrocyte through EMT and played important roles in the occurrence and development of IPF. As a result, we examined relationship between Nogo-b and EMT based on A549 cell models of Type II airway epithelial cells. Results showed that the increase of Nogo-b expression can enhance EMT of the cell.

The pathogenetic process of pulmonary fibrosis is very complicated, which is accompanied by accumulation of a great many extracellular matrix and abnormal expression of inflammatory factors. In this study, the results derived from GO and KEGG analyses on the model of a group of BLM-induced mice in GEO showed a number of DEGs were abundant in pathways such as
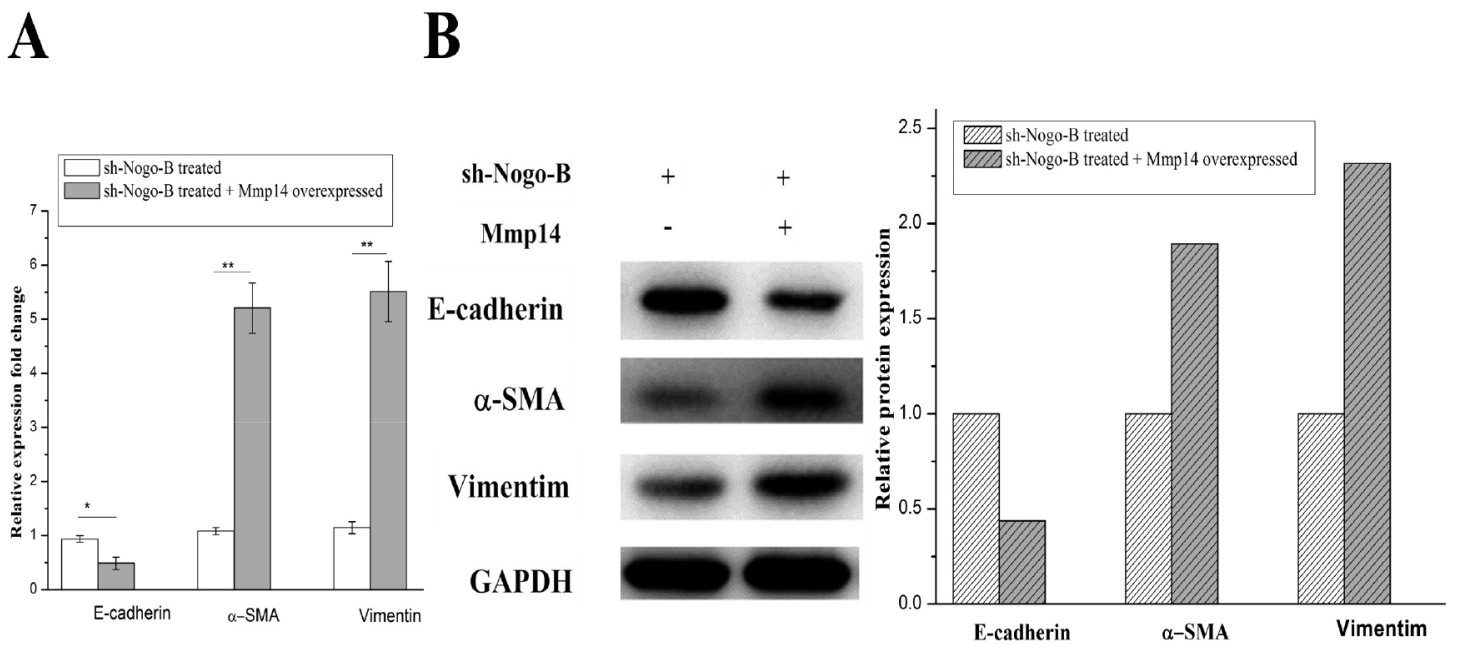

Figure 7: The EMT of the A549 cells with down-regulated Nogo-B were recovered by the up-regulated Mmp14. mRNA analysis (A) and immunoblot analysis (B) of marker proteins (E-cardherin, $\alpha$-SMA and Vimentin) which were relative to the EMT in the A549 cells treated with Mmp14 overexpressed and Nogo-b knock down. 
A

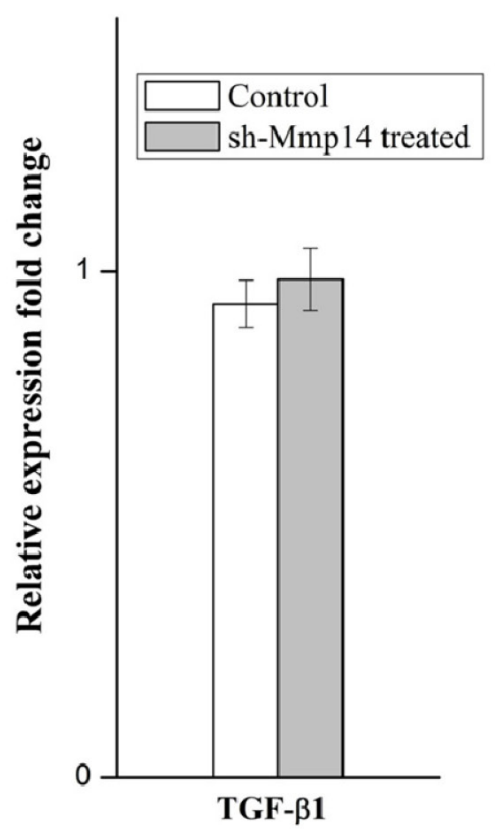

Supernatants

TGF- $\beta 1$
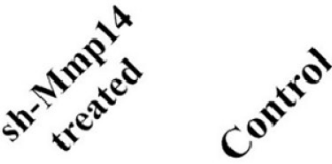

Supernatants

Cell lysates

\section{Proproteins}

\section{GAPDH}

Figure 8: MMP14 promote TGF- $\beta 1$ release from pro-proteins. (A) TGF- $\beta$ mRNA expression was quantified in the MMP14 knock down A549 cell model. (B) Free TGF- $\beta 1$ in supernatants and TGF- $\beta$ proproteins in cell lysates were determined by Western blot.
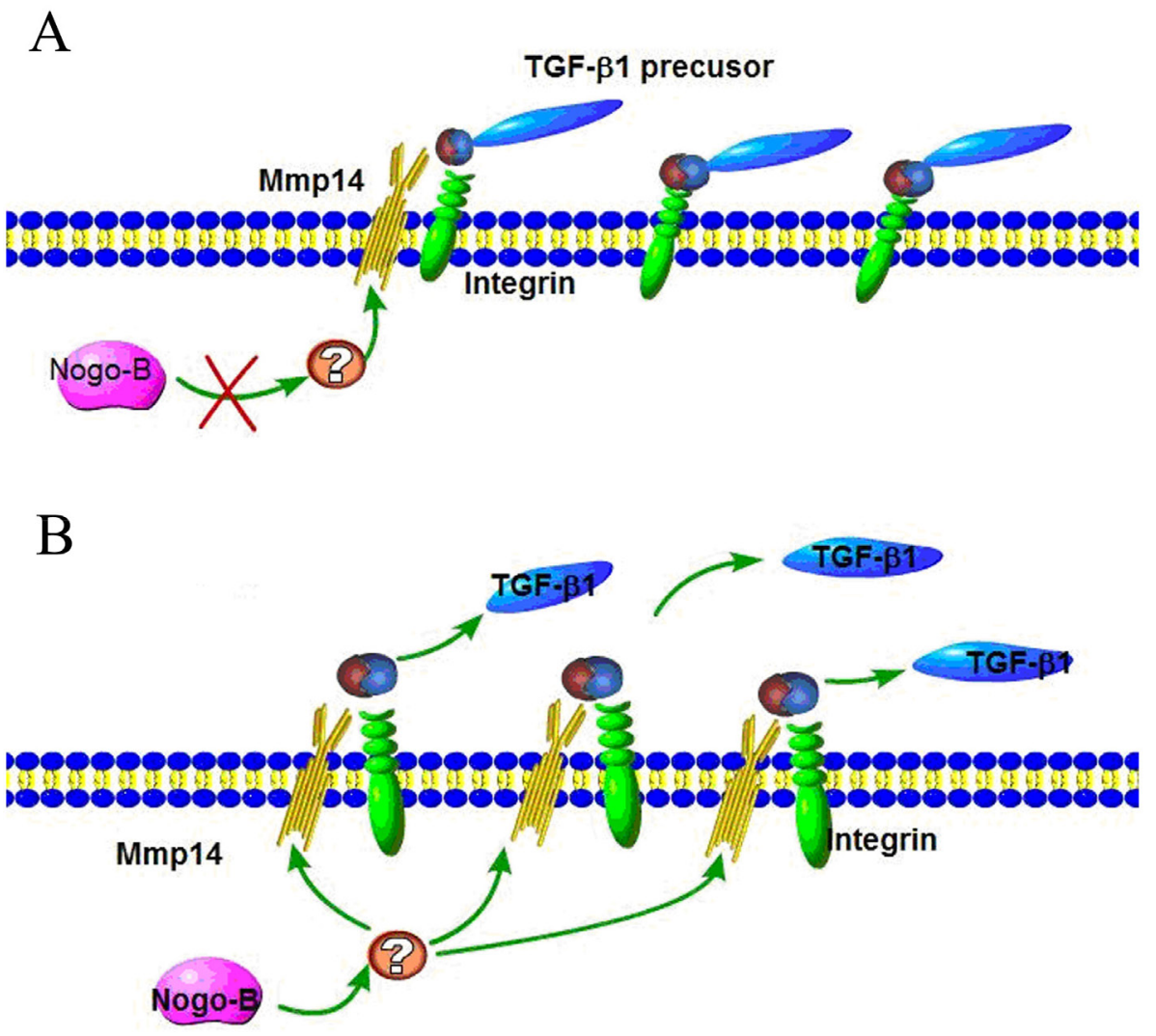

Figure 9: Activation of latent TGF by Nogo-b/MMP14 pathway. (A) The integrin binds RGD site of latent TGF which can be proteolytically digest by MMP14; (B) Nogo-b increased MMP14 promoted the proteolytically digest of latent TGF, permitting more active TGF $\beta 1$ distant from receptors. 
Table 2: RT-PCR primers

\begin{tabular}{|c|c|c|c|}
\hline & & Mus musculus & Homo sapiens \\
\hline \multirow[t]{2}{*}{$\mathrm{SOCS} 3$} & sense & 5'-ATCCTGGTGACAT GCTCCTC-3' & \\
\hline & anti-sense & 5'-CAAATGTTGCTTCCCCCTTA-3' & \\
\hline \multirow[t]{2}{*}{$\mathrm{Ccl} 9$} & sense & 5'-ATGAAGCCTTTTCATACTGCCCTC-3' & \\
\hline & anti-sense & 5'- TTATTGTTTGTAGGTCCGTG GTTG-3' & \\
\hline \multirow[t]{2}{*}{ Mmp14 } & sense & 5'- GCTCC GAGGAGAGATGTTTG-3' & 5'- GGAGACAAGCATTGGGTGTT-3' \\
\hline & anti-sense & 5'-CATCACTGCCCATG AATGAC-3' & 5'-GGTAGCCCGGTTCTACCTTC-3' \\
\hline \multirow[t]{2}{*}{ Igf1 } & sense & 5'-ACTGACATGCCCAAGACTCAGAAGTC-3' & \\
\hline & anti-sense & 5'-TGCCTCCGTTACCTCCTCCTGTTC-3' & \\
\hline \multirow[t]{2}{*}{ C1qa } & sense & 5'-ACAAGGTCCTCACCAACCAG-3' & \\
\hline & anti-sense & 5'-AAGATGCTGTCGGCTTCAGT-3' & \\
\hline \multirow[t]{2}{*}{$\mathrm{C} 1 \mathrm{qb}$} & sense & 5'-AGTGCCGGGCCTCTACTACT-3' & \\
\hline & anti-sense & 5'-CGGGAAACAGTAGGAAACCA-3' & \\
\hline \multirow[t]{2}{*}{$\mathrm{Ccl} 12$} & sense & 5'-ATCAGTCCTCAGGTATTGGCTGGA-3' & \\
\hline & anti-sense & 5'-TGGCTGCTTGTGATTCTCCTGTAG-3' & \\
\hline \multirow[t]{2}{*}{$\mathrm{Ccl} 2$} & sense & 5'-TTAAAAACCTGGATCGGAACCAA-3' & \\
\hline & anti-sense & 5'-GCATTAGCTTCAGATTTACGGGT-3' & \\
\hline \multirow[t]{2}{*}{$\mathrm{Ccl} 8$} & sense & 5'-AGCCCAGGCACCATCTGCTTGTAA-3' & \\
\hline & anti-sense & 5'-TGCCCCATGGAAGCTGTGGTTTTC-3' & \\
\hline \multirow[t]{2}{*}{$\mathrm{Cxcl} 10$} & sense & 5'-TCAGCACCATGAACCCAAG-3' & \\
\hline & anti-sense & 5'-CTATGGCCCTCATTCTCACTG-3' & \\
\hline \multirow[t]{2}{*}{ Gsta2 } & sense & 5'-TTATGTCCCCCAGACCAAAG-3' & \\
\hline & anti-sense & 5'-CCTGTTGCCCACAAGGTAGT-3' & \\
\hline \multirow[t]{2}{*}{ Gapdh } & sense & 5'-CCTTCATTGACCTCAACTAC-3' & \\
\hline & anti-sense & 5'-TGGGCCCTCAGATGCCTGCT-3' & \\
\hline \multirow[t]{2}{*}{ RTN4 } & sense & & 5'-GGAGCTGCAAAGCAGATCGTGAC-3' \\
\hline & anti-sense & & 5'-GGCTGGCACCAAACACCACTCC-3' \\
\hline
\end{tabular}

interactions of inflammatory factors and extracellular matrix by the comparison of the BLM-induced model and the control model. Subsequently, we found that MMP14 abundant in extracellular matrix and TNF signaling pathway was significantly increased in the pulmonary fibrosis model induced by bleomycin via RT-PCR verification. MMP14, a kind of matrix metalloproteinase, is regarded as a major effect factor for the degradation of extracellular matrix and core matrisome proteins [31-32]. In general, the MMP14 shows low activity under normal conditions [33]. While during the course of repairing and reconstruction, its expression is increased and leading to high corresponding activity [33-34]. A great number of researches have shown that MMP family expresses at a high level in complicated fibrosis diseases including IPF [35-37]. However, the problem that whether MMP14 plays an important role in IPF has never been discussed before.

It has been reported by many researchers that MMP14 has played a crucial role in tumor growth and migration process of EMT dependence [38]. In addition, MMP14 was known as Dexamethasone-dependent biomarker of EMT in primary hepatocytes [31]. In this article, we discovered that the over-expression of MMP14 in A549 cells could intensify EMT of cells, similar to the role of positive control of TGF- $\beta 1$. However, cells of MMP14 knock down were decreased in EMT capacities. These results revealed that MMP14 could enhance the EMT activity of cells and 
consequently resulted in the occurrence and development of pulmonary fibrosis. Moreover, we discussed the correlation between Nogo-b and MMP14, both of which were molecules that could promote EMT and cause pulmonary fibrosis. Results showed that Nogo-b was a upstream controlling factor of MMP14. The over-expression of Nogo-b could increase the expression of MMP14 as well as intensify the EMT of cells. While the increase or reduction of MMP14 would not exert any influence on expression of Nogo-b. In addition, we also found that the increase of MMP14 could recover the weakening of EMT arising from the silence of Nogo-b and the reduction of MMP14 could weaken the strengthening of EMT caused by Nogo-b. Therefore, we could draw a conclusion that Nogo-b relied on MMP14 to intensify the EMT for airway epithelial cells.

TGF- $\beta 1$, which can enhance EMT of numerous cells, plays a key role in the process of pulmonary fibrosis [1, 12, 39]. Previous researches revealed that Nogo-b could cause hepatic fibrosis through TGF $\beta 1 /$ Smad2 signaling pathway [40]. Likewise, it was reported that MMP14 could increase activity of TGF $\beta 1 / \mathrm{Smad} 2$ signaling pathway and raise stem cells in injured artery blood vessels to repair damages [41]. Furthermore, literatures previously showed that MMP14 could perform enzyme cleavage on TGF $\beta$ precursor proteins to release free TGF $\beta 1$ [42-43]. In this article, we discovered that MMP14 was controlled and regulated by Nogo-b and was correlated to pulmonary fibrosis. Hence, we hypothesized that Nogo-b/MMP14 signaling pathway was affecting the process of pulmonary fibrosis by influencing the TGF $\beta 1$ signaling pathway. We also proved our hypothesis. Results showed that reduction of MMP14 expression would neither affect the mRNA expression of TGF- $\beta 1$ nor the expression of TGF $\beta$ precursor proteins. Instead, it would decline the release of free TGF- $\beta 1$. All these results indicated that Nogo-b/MMP14 signaling pathway actually relied on the enhancement of enzyme cleavage of TGF $\beta$ precursor proteins rather than the influences on mRNA expression to affect the EMT of airway epithelial cell and pulmonary fibrosis.

In conclusion, MMP14/Nogo-b pathway serves as a new driver factor of the EMT process in BLM-induced pulmonary fibrosis, which can intensify EMT of cells by stimulating release of free TGF- $\beta 1$. These findings can help us deeply understand the pathogenesis of IPF. In addition, the therapeutic schedule specific to MMP14/Nogo-b may effectively relieve the symptoms of pulmonary fibrosis, which is the task our team plans to work on.

\section{MATERIALS AND METHODS}

\section{Establishment of a mouse model of BLM- induced pulmonary fibrosis}

A total of 35 8-week-old male C57BL/6 mice were purchased from the Slaccas Experimental Animal
Company (Shanghai, China). All animal experiments were carried out with approval from the Ethics Committee of Changhai Hosiptial. The mice were divided into the following 2 groups: i) The control group, ii) The group treated with BLM. Way of treatment with BLM (HisunPfizerPharmaceuticals Co., Ltd., Zhejiang, China) is as follows: 8 -week-old mice were anesthetized with isoflurane. BLM $(10 \mathrm{mg} / \mathrm{kg}$ body weight in 50 $\mu$ saline) was delivered into the oropharyngeal cavity after the tongues of the anesthetized mice were gently pulled forward. Tongues were kept pulled forward until intratracheal injection was completed. The mice in the control group without BLM treatment were injected with saline as the above steps. The mice were killed after 28 days, lung tissues of which were used for subsequent analysis.

\section{Masson staining}

After mice were sacrificed, lungs were harvested, embedded in paraffin and then deparaffinized, followed by Masson staining for the observation of lung fibrosis.

\section{Immunohistochemistry (IHC)}

Lung samples were fixed in formalin solution and embedded by paraffin. Paraffin blocks were cut into $4 \mu \mathrm{m}-$ thickness sections and then incubated in the 3\% hydrogen peroxide solution to eliminate endogenous peroxidase activities. Antigen retrieval was carried out by heat mediationin method in citrate buffer solution $(\mathrm{pH}=6)$. Sections were closed in the $10 \%$ goat serum solution before being incubated in primary antibody containing Nogo-b (Abcam) overnight at a temperature of $4^{\circ} \mathrm{C}$. PBS without primary antibodies was applied as the negative control. Immunohistochemical staining was performed with the 3-3'-diaminobenzidine [44] and then counterstain was followed by hematoxylin. The immunohistochemistry results were graded and classified into two groups according to the average staining intensity and area.

\section{Data analysis}

The microarray data GSE25640, downloaded from Gene Expression Omnibus (GEO) database, was sequencing upon the platform of Affymetrix Mouse Genome 430 2.0 Array. This dataset was stored by Turashvili et al [20], It has 12 gene microarray data, including those for lungs of 6 wild type mice and 6 FIZZZ2 knockout mice. We picked out information for 6 wild type samples, among which three mice were treated with bleomycin and other three were not. The original CEL data was imported into $\mathrm{R}$ program and processed by affy package to correct and normalize the background. Moreover, multiple probe data used to inspect the expression of the same gene was summarized. Different Expression Genes (DEGs) between the bleomycin- treated 
group and the bleomycin-untreated group were identified using Limma package [22]. The p-value no more than 0.05 and |log2fold change| larger than 1 were regarded as the screen threshold value of the DEG.

\section{Cell culture and overexpression}

The Type II alveolar epithelial cells A549 were cultivated in the DMEM culture medium containing 10\% of fetal bovine serum (Gibco, USA). Cells were placed in a standard humidity incubator with a temperature of $37^{\circ} \mathrm{C}$ and containing $5 \%$ of $\mathrm{CO}_{2}$. TGF- $\beta 1$ (Sigma-Aldrich, USA) was added and the final concentration of the culture medium is $10 \mathrm{ng} / \mathrm{ml}$. The cells were cultured in the medium containing TGF- $\beta 1$ for 48 hours before being collected for further analysis.

A total of 1ug of pcDNA-3.1-MMP14, pcDNA-3.1Nogo-b plasmid was diluted in $50 \mu \mathrm{l}$ of RPMI 1640 medium free of serum and $2 \mu \mathrm{l}$ of Lipofectamine ${ }^{\circledR} 2000$ was diluted in $50 \mu \mathrm{l}$ of RPMI 1640 medium free of serum. Then mix the above two solutions and add the mixture into the A549 cell contained in the 24-well plate for transfection. After incubation at $37^{\circ} \mathrm{C}$ for 4 hours, the serum-free medium was substituted by a complete medium containing $10 \%$ of serum. Culture it for another 48 hours. The cells were then collected for subsequent experiments. After transfection for 48 hours, inspect expressions of mRNA and protein based on the technologies of real-time PCR and Western blotting.

\section{Nogo-b and MMP14 knock down}

pLKO. 1 plasmid was digested with EcoRI and AgeI. The short hairpin RNA (shRNA) carrier was constructed to target Nogo-b gene by inserting the sequence of 5'-CC GGGCAGTGTTGATGTGGGTATTTCTCGAGAAATA CCCACATCAACACTGCTTTTTTG into the plasmid pLKO.1. The targeting of MMP14 plasmid was set up by inserting the sequence of 5'-CCGGGTGGATGGACAC GGAGAATTTCTCGAGAAATTCTCCGTGTCCATCC ACTTTTTG. Plasmids were then transfected into A549 cell. Stable cell lines of Nogo-b with low expression were screened and obtained by puromycin.

\section{Real-time PCR}

Real-time PCR was analyzed by LightCycler ${ }^{\circledR} 480$ Real-Time PCR system (Roche, Switzerland) with reagent of SYBR PrimeScriptTM RT Reagent Kit (TaKaRa, Japan). All the operation should follow the manufacturer's operation manual. The primers and reaction conditions are shown in Table 2.

\section{Western blotting analysis}

The protein concentration was determined using the Bio-Rad protein assay system. Cells receiving different treatment were dissolved in Laemmli buffer and boiling for
5 minutes. 20ug of protein was subjected to electrophoresis in $12 \%$ of SDS-PAGE and then transferred to nitrocellulose membrane. Keep it closed in PBS containing 5\% skimmed milk for 2 hours at room temperature and then add different primary antibodies including Nogo-b (Abcam, dulited in PBS with 1:1000); MMP14 (Santa Cruz, dulited in PBS with 1:200); E-cadherin; vimentin or $\alpha$-SMA both from ImmunoWay Biotechnology Company, dulited in PBS with 1:1000; GAPDH was regarded as the internal refere nce, dulited in PBS with 1:1000. After washing, the membranes were incubated in the corresponding secondary antibody for 1 hour at room temperature, followed by chemiluminescence testing strips.

\section{Statistical analysis}

All data are presented as the means \pm standarddeviation (SD). Comparisons among groups wereperformed by one-way ANOVA using SPSS 17.0 software (SPSS, Inc., Chicago, IL, USA). All experiments were repeatedthree times. $\mathrm{P}<0.05$ was considered to indicate a statistically significant difference.

\section{Author contributions}

Conceived and designed the experiments: Ye Xiong, Guo-WuZhouandQiang L.

Performed the experiments: Ye Xiong, Jing Zhang, Lingzhi ShiandYunye Ning.

Analyzed the data: Ying Zhu, YeXiong, Jing Zhang and Lingzhi Shi.

Contributed reagents/materials/analysis tools: $\mathrm{Si}$ Chen, Meng Yang andJingyu Chen.

Drafted the manuscript: Jing Zhang and GuoWuZhou.

\section{CONFLICTS OF INTEREST}

The authors confirm that this article content has no Competing interests.

\section{FUNDING}

This work was supported by National Natural Science Funds for Young Scholar, No.81400048.

\section{REFERENCES}

1. Wynn TA. Cellular and molecular mechanisms of fibrosis. J Pathol. 2008; 214:199-210.

2. Spagnolo P, Grunewald J, du Bois RM. Genetic determinants of pulmonary fibrosis: evolving concepts. Lancet Respir Med. 2014; 2:416-28.

3. Selman M, Pardo A, Kaminski N. Idiopathic pulmonary fibrosis: aberrant recapitulation of developmental programs? PLoS Med. 2008; 5:e62. 
4. Rajasekaran S, Rajaguru P, Sudhakar Gandhi PS. MicroRNAs as potential targets for progressive pulmonary fibrosis. Front Pharmacol. 2015; 6:254.

5. Willis BC, Liebler JM, Luby-Phelps K, Nicholson AG, Crandall ED, du Bois RM, Borok Z. Induction of epithelial-mesenchymal transition in alveolar epithelial cells by transforming growth factor-beta1: potential role in idiopathic pulmonary fibrosis. Am J Pathol. 2005; 166:1321-32.

6. Kim KK, Kugler MC, Wolters PJ, Robillard L, Galvez MG, Brumwell AN, Sheppard D, Chapman HA. Alveolar epithelial cell mesenchymal transition develops in vivo during pulmonary fibrosis and is regulated by the extracellular matrix. Proc Natl Acad Sci U S A. 2006; 103:13180-5.

7. Gonzalez-Cortes C, Salinas-Lara C, Gomez-Lopez MA, Tena-Suck ML, Perez-De La Cruz V, Rembao-Bojorquez D, Pedraza-Chaverri J, Gomez-Ruiz C, Galvan-Arzate S, Ali SF, Santamaria A. Iron porphyrinate Fe(TPPS) reduces brain cell damage in rats intrastriatally lesioned by quinolinate. Neurotoxicol Teratol. 2008; 30:510-9.

8. Shen J, Song G, An M, Li X, Wu N, Ruan K, Hu J, Hu $\mathrm{R}$. The use of hollow mesoporous silica nanospheres to encapsulate bortezomib and improve efficacy for non-small cell lung cancer therapy. Biomaterials. 2014; 35:316.

9. Jayachandran A, Konigshoff M, Yu H, Rupniewska E, Hecker M, Klepetko W, Seeger W, Eickelberg O. SNAI transcription factors mediate epithelial-mesenchymal transition in lung fibrosis. Thorax. 2009; 64:1053-61.

10. Kage H, Borok Z. EMT and interstitial lung disease: a mysterious relationship. Curr Opin Pulm Med. 2012; 18:517-23.

11. Wang YC, Liu JS, Tang HK, Nie J, Zhu JX, Wen LL, Guo QL. miR221 targets HMGA2 to inhibit bleomycininduced pulmonary fibrosis by regulating TGFbeta1/Smad3-induced EMT. Int J Mol Med. 2016; 38:1208-16.

12. Fernandez IE, Eickelberg O. The Impact of TGF- $\beta$ on Lung Fibrosis. Proc Am Thorac Soc. 2012; 9:111-6.

13. Gharaee-Kermani M, Phan SH. Molecular mechanisms of and possible treatment strategies for idiopathic pulmonary fibrosis. Curr Pharm Des. 2005; 11:3943-71.

14. Acevedo L, Yu J, Erdjument-Bromage H, Miao RQ, Kim JE, Fulton D, Tempst P, Strittmatter SM, Sessa WC. A new role for Nogo as a regulator of vascular remodeling. Nat Med. 2004; 10:382-8.

15. Yu J, Fernándezhernando $\mathrm{C}$, Suarez Y, Schleicher M, Hao Z, Wright PL, Dilorenzo A, Kyriakides TR, Sessa WC. Reticulon 4B (Nogo-B) is necessary for macrophage infiltration and tissue repair. Proc Natl Acad Sci U S A. 2009; 106:17511-6.

16. Zhang D, Utsumi T, Huang HC, Gao L, Sangwung P, Chung C, Shibao K, Okamoto K, Yamaguchi K, Groszmann RJ. Reticulon 4B (Nogo-B) is a novel regulator of hepatic fibrosis. Hepatology. 2011; 53:1306-15.
17. Xu W, Hong W, Yan S, Ning Y, Cai Z, Qiang L. Nogo-B regulates migration and contraction of airway smooth muscle cells by decreasing ARPC $2 / 3$ and increasing MYL-9 expression. Respir Res. 2011; 12:14.

18. Yan T, Lin Z, Jiang J, Lu S, Chen M, Que H, He X, Que G, Mao J, Xiao J, Zheng Q. MMP14 regulates cell migration and invasion through epithelial-mesenchymal transition in nasopharyngeal carcinoma. Am J Transl Res. 2015; 7:950-8.

19. Li W, Li S, Deng L, Yang S, Li M, Long S, Chen S, Lin F, Xiao L. Decreased MT1-MMP in gastric cancer suppressed cell migration and invasion via regulating MMPs and EMT. Tumour Biol. 2015; 36:6883-9.

20. Bohrnsen F, Fricke M, Sander C, Leha A, Schliephake H, Kramer FJ. Interactions of human MSC with head and neck squamous cell carcinoma cell line PCI-13 reduce markers of epithelia-mesenchymal transition. Clin Oral Investig. 2015; 19:1121-8.

21. Zuo QF, Cao LY, Yu T, Gong L, Wang LN, Zhao YL, Xiao B, Zou QM. MicroRNA-22 inhibits tumor growth and metastasis in gastric cancer by directly targeting MMP14 and Snail. Cell Death Dis. 2015; 6:e2000.

22. Jiang W, Zhang Y, Kane KT, Collins MA, Simeone DM, Pasca dMM, Nguyen KT. CD44 Regulates Pancreatic Cancer Invasion through MT1-MMP. Mol Cancer Res. 2015; 13:9.

23. Liu T, Baek HA, Yu H, Lee HJ, Park BH, Ullenbruch M, Liu J, Nakashima T, Choi YY, Wu GD, Chung MJ, Phan $\mathrm{SH}$. FIZZ2/RELM-beta induction and role in pulmonary fibrosis. J Immunol. 2011; 187:450-61.

24. Rodriguez-Feo JA, Gallego-Delgado J, Puerto M, Wandosell F, Osende J. Reticulon-4B/Nogo-B acts as a molecular linker between microtubules and actin cytoskeleton in vascular smooth muscle cells. Biochim Biophys Acta. 2016; 1863:1985-95.

25. Xu WJ, Shen GQ, Li Q. [Biological function of Nogo-B]. Sheng Li Xue Bao. 2013; 65: 445-50. [Article in Chinese].

26. Xu W, Zhu Y, Ning Y, Dong Y, Huang H, Zhang W, Sun Q, Li Q. Nogo-B protects mice against lipopolysaccharideinduced acute lung injury. Scientific Reports. 2015; 5:12061.

27. Comeglio P, Filippi S, Sarchielli E, Morelli A, Cellai I, Corcetto F, Corno C, Maneschi E, Pini A, Adorini L, Vannelli GB, Maggi M, Vignozzi L. Anti-fibrotic effects of chronic treatment with the selective FXR agonist obeticholic acid in the bleomycin-induced rat model of pulmonary fibrosis. J Steroid Biochem Mol Biol. 2017; 168:26-37.

28. Della Latta V, Cecchettini A, Del Ry S, Morales MA. Bleomycin in the setting of lung fibrosis induction: From biological mechanisms to counteractions. Pharmacol Res. 2015; 97:122-30.

29. Moeller A, Ask K, Warburton D, Gauldie J, Kolb M. The bleomycin animal model: a useful tool to investigate 
treatment options for idiopathic pulmonary fibrosis? Int $\mathrm{J}$ Biochem Cell Biol. 2008; 40:362-82.

30. Dong Y, Geng Y, Li L, Li X, Yan X, Fang Y, Li X, Dong S, Liu X, Li X, Yang X, Zheng X, Xie T, et al. Blocking follistatin-like 1 attenuates bleomycin-induced pulmonary fibrosis in mice. J Exp Med. 2015; 212:235-52 .

31. Godoy P, Lakkapamu S, Schug M, Bauer A, Stewart JD, Bedawi E, Hammad S, Amin J, Marchan R, Schormann W, Maccoux L, von Recklinghausen I, Reif R, et al. Dexamethasone-dependent versus -independent markers of epithelial to mesenchymal transition in primary hepatocytes. Biol Chem. 2010; 391:73-83.

32. Apte SS, Fukai N, Beier DR, Olsen BR. The matrix metalloproteinase-14 (MMP-14) gene is structurally distinct from other MMP genes and is co-expressed with the TIMP-2 gene during mouse embryogenesis. J Biol Chem. 1997; 272:25511-7.

33. Oblander SA, Zhou ZJ, Galvez BG, Starcher B, Shannon JM, Durbeej M, Arroyo AG, Tryggvason K, Apte SS. Distinctive functions of membrane type 1 matrixmetalloprotease (MT1-MMP or MMP-14) in lung and submandibular gland development are independent of its role in pro-MMP-2 activation. Dev Biol. 2005; 277:255-69.

34. He H, Tang H, Gao L, Wu Y, Feng Z, Lin H, Wu T. Tanshinone IIA attenuates bleomycin-induced pulmonary fibrosis in rats. Mol Med Rep. 2015; 11:4190.

35. Henry MT, McMahon K, Mackarel AJ, Prikk K, Sorsa T, Maisi P, Sepper R, FitzGerald MX, O'Connor CM. Matrix metalloproteinases and tissue inhibitor of metalloproteinase-1 in sarcoidosis and IPF. Eur Respir J. 2002; 20:1220-7.

36. Lemjabbar H, Gosset P, Lechapt-Zalcman E, FrancoMontoya ML, Wallaert B, Harf A, Lafuma C. Overexpression of alveolar macrophage gelatinase B (MMP-9) in patients with idiopathic pulmonary fibrosis - Effects of steroid and immunosuppressive treatment. Am J Respir Cell Mol Biol. 1999; 20:903-13.

37. McKeown S, Richter AG, O'Kane C, McAuley DF, Thickett DR. MMP expression and abnormal lung permeability are important determinants of outcome in IPF. Eur Respir J. 2009; 33:77-84.

38. Radisky ES, Radisky DC. Matrix MetalloproteinaseInduced Epithelial-Mesenchymal Transition in Breast Cancer. J Mammary Gland Biol Neoplasia. 2010; 15:201-12.

39. Leask A, Abraham DJ. TGF-beta signaling and the fibrotic response. FASEB J. 2004; 18:816-27.

40. Xiao W, Zhou S, Xu H, Li H, He G, Liu Y, Qi Y. Nogo-B promotes the epithelial-mesenchymal transition in HeLa cervical cancer cells via Fibulin-5. Oncol Rep. 2013; 29:109-16

41. Pang L, Wei C, Duan J, Zou H, Cao W, Qi Y, Jia W, Hu J, Zhao W, Jiang J, Liang W, Li F. TGF-beta1/Smad signaling, MMP-14, and MSC markers in arterial injury: discovery of the molecular basis of restenosis. Int J Clin Exp Pathol. 2014; 7:2915-24.

42. Jenkins $\mathrm{G}$. The role of proteases in transforming growth factor-beta activation. Int J Biochem Cell Biol. 2008; 40:1068-78.

43. Sounni NE, Dehne K, van Kempen L, Egeblad M, Affara NI, Cuevas I, Wiesen J, Junankar S, Korets L, Lee J, Shen J, Morrison CJ, Overall CM, et al. Stromal regulation of vessel stability by MMP14 and TGF beta. Dis Model Mech. 2010; 3:317-32.

44. Peng Q, Collette W 3rd, Giddabasappa A, David J, Twamley M, Kalabat D, Aguirre SA, Huang W. Editor's Highlight: Plasma miR-183/96/182 Cluster and miR-124 are Promising Biomarkers of Rat Retinal Toxicity. Toxicol Sci. 2016; 152:273-83. 